\title{
Evidence-based assessment of potential use of fingolimod in treatment of relapsing multiple sclerosis
}

This article was published in the following Dove Press journal:

Core Evidence

31 December 2010

Number of times this article has been viewed

\section{Emilio Portaccio \\ Department of Neurology, University of Florence, Florence, Italy}

\begin{abstract}
Multiple sclerosis is an autoimmune inflammatory demyelinating disease of the central nervous system and represents one of the most common causes of chronic neurologic disability in young adults. All the current disease-modifying drugs are administered parenterally, and can be associated with varying degrees of injection site or infusion-related reactions. Together with other side effects, the parenteral route of administration is one of the key factors affecting adherence to therapy in multiple sclerosis. Fingolimod (FTY720) is an immunomodulator that acts on sphingosine 1-phosphate (S1P) receptors and is the first oral drug approved by the US Food and Drug Administration for the treatment of relapsing-remitting multiple sclerosis. Downmodulation of $\mathrm{S} 1 \mathrm{P}$ receptor type $1\left(\mathrm{~S}_{1} \mathrm{P}_{1}\right)$ slows the egress of lymphocytes from lymph nodes and recirculation to the central nervous system, reduces astrogliosis, and inhibits angiogenesis during chronic neuroinflammation. Fingolimod also regulates the migration of B cells and dendritic cells, and enhances endothelial barrier function. Results from Phase II and III clinical trials provide robust evidence of the efficacy of fingolimod in relapsing-remitting multiple sclerosis. While some caution should be exercised in terms of safety issues, the introduction of fingolimod represents a great advance in the treatment of relapsing-remitting multiple sclerosis. The pharmacologic data on fingolimod and its efficacy and safety in multiple sclerosis are reviewed in this paper.
\end{abstract}

Keywords: FTY720, fingolimod, S1P receptors, oral treatment, multiple sclerosis

\section{Core Evidence clinical impact summary for [fingolimod/relapsing multiple sclerosis]}

\begin{tabular}{|c|c|c|}
\hline Outcome measure & Evidence & Implications \\
\hline Disease-oriented evidence & & Clear efficacy in relapsing- \\
\hline Clinical & $\begin{array}{l}54 \% \text { reduction compared } \\
\text { to placebo* }\end{array}$ & $\begin{array}{l}\text { remitting multiple sclerosis } \\
\text { as measured on both }\end{array}$ \\
\hline Annualized & $52 \%$ reduction compared & clinical and MRI \\
\hline Relapse-rate & to IFNB-Ia i.m. ${ }^{\S}$ & parameters. \\
\hline EDSS progression & $\begin{array}{l}\text { HR for disease progression } \\
\text { confirmed after } 6 \text { months }=0.63^{*}\end{array}$ & $\begin{array}{l}\text { It may promote the } \\
\text { prevention } \\
\text { of disability accumulation }\end{array}$ \\
\hline MRI & & and disease progression \\
\hline Brain volume & $\begin{array}{l}\text { Approximately } 30 \% \text { reduction in the } \\
\text { rate of brain atrophy }{ }^{* \S}\end{array}$ & $\begin{array}{l}\text { overtime (long-term } \\
\text { follow-up studies }\end{array}$ \\
\hline $\begin{array}{l}\text { No. of gadolinium-enhancing } \\
\text { lesions }\end{array}$ & $\begin{array}{l}\text { Significant reduction compared to } \\
\text { placebo and IFNB Ia i.m. }{ }^{*}\end{array}$ & are needed). \\
\hline \multirow{2}{*}{\multicolumn{3}{|c|}{$\begin{array}{l}\text { No. of new or enlarged } \\
\text { lesions on } \mathrm{T} 2 \text {-weighted images }\end{array}$}} \\
\hline & & \\
\hline & & (Continued) \\
\hline
\end{tabular}

Correspondence: Emilio Portaccio

Viale Morgagni 85,

50134 Florence, Italy

Tel +390557947122

Fax +390557947287

Email portilio@tin.it 


\begin{tabular}{|c|c|c|}
\hline \multicolumn{3}{|l|}{ (Continued) } \\
\hline Outcome measure & Evidence & Implications \\
\hline \multicolumn{3}{|c|}{ Patient-oriented evidence } \\
\hline Discontinuation rate & $\begin{array}{l}10.2 \% \text { at } 12 \text { months }^{\S} \\
16.8 \% \text { at } 24 \text { months }^{*}\end{array}$ & $\begin{array}{l}\text { High rate of adherence, } \\
\text { mainly due to the oral } \\
\text { administration and } \\
\text { the good tolerability. It } \\
\text { may promote the efficacy } \\
\text { of the drug in the long- } \\
\text { term. }\end{array}$ \\
\hline \multirow{3}{*}{$\begin{array}{l}\text { Quality of life measures } \\
\text { Economic evidence }\end{array}$} & Not available & \\
\hline & & \\
\hline & Not available & \\
\hline
\end{tabular}

\section{Introduction}

Multiple sclerosis is an autoimmune inflammatory demyelinating disease of the central nervous system, and is one of the most common causes of chronic neurologic disability in young adults. ${ }^{1}$ It typically affects people during the most productive period of their lives, with a peak onset at age $20-40$ years. In the majority of cases $(80 \%-90 \%)$, the disease at onset is characterized by a relapsing-remitting course, in which episodes of acute relapse, followed by full or partial recovery, are separated by periods of remission. In most patients, the relapsing-remitting phase is followed by a secondary progressive course, in which disability progressively accumulates despite the absence of acute exacerbations. In a smaller proportion of cases $(10 \%-20 \%)$, the disease starts with a primary progressive course, and disability progressively increases from the onset onwards. ${ }^{1}$ The pathogenesis of multiple sclerosis is still far from a full definition. However, evidence points to a multifactorial etiology, in which genetic and environmental factors contribute to the genesis of the disease. In terms of mechanisms, a large body of data indicates that myelin destruction, loss of oligodendrocytes, and varying degrees of axonal injury are sustained by the

Table I Escalating therapy of multiple sclerosis

\begin{tabular}{ll}
\hline First-line therapies & Interferon-beta \\
& Glatiramer acetate \\
& (Azathioprine) \\
Second-line therapies & Mitoxantrone \\
& Natalizumab \\
& Cyclophosphamide \\
Third-line therapy & Hematopoietic autologous \\
& Stem cell transplantation \\
\hline
\end{tabular}

involvement of immunologic factors. In particular, both cellular and humoral immune mechanisms play a central role in the genesis of the disease. ${ }^{1-3}$

To date, there is no cure for multiple sclerosis. However, over the last two decades, several therapies have been developed, leading to a significant improvement in the clinical outcome of the disease. ${ }^{1}$ These include the three different formulations of interferon- $\beta$ (IFN- $\beta$ ), and glatiramer acetate, mitoxantrone, and natalizumab. According to currently accepted treatment protocols, IFN- $\beta$ and glatiramer acetate are considered to be first-line treatments for relapsingremitting multiple sclerosis, while mitoxantrone and natalizumab are considered second-line therapies which are generally reserved for patients who do not respond to the first-line agents or who cannot tolerate their side effects (Table 1). ${ }^{4}$

These therapies are mainly indicated for treatment of relapsing-remitting multiple sclerosis, for which clinical trials have shown a clear efficacy. Evidence of efficacy of immunomodulatory and immunosuppressive therapies in the progressive phases of the disease are more limited, and only mitoxantrone and IFN- $\beta 1 \mathrm{~b}$ (the latter in Europe only) have been approved for secondary progressive multiple sclerosis.

IFN- $\beta 1 b$ is the first immunomodulatory drug available for multiple sclerosis, and was approved by the US Food and Drug Administration (FDA) in 1993. ${ }^{5}$ Other formulations of IFN- $\beta$ were approved in the following years, between 1996 and 2002. ${ }^{6,7}$ The other immunomodulatory drug, glatiramer acetate, was approved in $1996 .{ }^{8}$ Both IFN- $\beta$ and glatiramer acetate have documented clinical efficacy in relapsingremitting multiple sclerosis. They reduce the relapse rate by about $30 \%$ and the accumulation of lesion load on brain magnetic resonance imaging (MRI) by about 70\%..$^{5-9}$ Their 
efficacy has been largely comparable in head-to-head trials. ${ }^{10,11}$ Second-line therapies have higher efficacy than immunomodulatory drugs. Mitoxantrone, a chemotherapeutic agent, was approved in 2000 for relapsing-remitting multiple sclerosis and early secondary progressive multiple sclerosis. It reduces the relapse rate by approximately $42 \%$ and accumulation of MRI lesion load by approximately $83 \% .^{12}$ However, its use is limited due to cumulative cardiotoxicity and an increased incidence of acute leukemia. ${ }^{12}$

Natalizumab was initially approved in 2004. It reduces the relapse rate by $68 \%$ and occurrence of new lesions on brain MRI of $83 \% .{ }^{9}$ However, it was voluntarily withdrawn from the market by the manufacturer after three cases of progressive multifocal leukoencephalopathy were reported. ${ }^{9}$ After further review by the FDA, natalizumab returned to the market in 2006 but under a special prescribing program intended to monitor strictly the safety of the drug and the occurrence of new cases of progressive multifocal leukoencephalopathy over time. The prescribing program was initiated and promoted by the manufacturer. Similarly, other prescribing and monitoring programs have been developed. For instance, in Italy, the national drug agency (Agenzia Italiana per il Farmaco) has created a registry to assess the safety of natalizumab in all treated cases. ${ }^{13-15}$

All the current disease-modifying drugs are administered parenterally, and can be associated with varying degrees of injection site or infusion-related reactions. Together with other side effects, the parenteral route of administration is one of the key factors affecting adherence to therapy for multiple sclerosis. ${ }^{16}$ Therefore, there is a need for the development of oral agents. The new generation of multiple sclerosis therapeutics includes fingolimod (Novartis Pharmaceuticals) and cladribine (Merck Serono), that are in a more advanced stage of development. Other oral agents, currently in Phase III trials, are BG00012, a fumarate ester (Biogen), laquinimod (Teva Pharmaceuticals), and teriflunomide (Sanofi-aventis). ${ }^{17}$

Cladribine is now under review by the FDA. Cladribine is an antineoplastic agent that is currently used to treat hairy cell leukemia. An oral formulation of cladribine has been

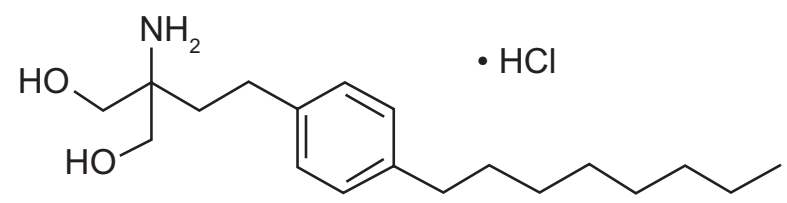

Figure I Chemical structure of FTY720 hydrochloride. tested in a single Phase III trial and was found to meet its primary endpoint. Indeed, there was a $58 \%$ relative reduction in annualized relapse rates compared with placebo. ${ }^{18}$ Fingolimod, a nonselective sphingosine 1-phosphate (S1P) receptor modulator, ${ }^{19}$ has been recently reviewed and approved by the FDA. ${ }^{20}$ Therefore, it is expected to be the first oral immunodulatory agent for multiple sclerosis to be launched. In the following sections we review pharmacologic aspects of fingolimod and data on its efficacy and safety in multiple sclerosis.

\section{Fingolimod}

Fingolimod (FTY720) is the prototype S1P receptor modulator, and is a derivative of a natural product, myriocin, isolated from the ascomycete Isaria sinclairii. ${ }^{21} \mathrm{~S} 1 \mathrm{P}$ is a sphingomyelin-derived second messenger that mediates several cellular responses, including proliferation, migration, cytoskeletal organization, and cell survival. ${ }^{22}$ It acts in both an autocrine and paracrine fashion by binding to five $\mathrm{G}$ protein-coupled receptors $\left(\mathrm{S}_{1} \mathrm{P}_{1}-\mathrm{S}_{1} \mathrm{P}_{5}\right)$. The different isoforms of S1P receptors are unevenly expressed in humans. $\mathrm{S}_{1} \mathrm{P}_{1}, \mathrm{~S}_{1} \mathrm{P}_{2}$, and $\mathrm{S}_{1} \mathrm{P}_{3}$ are widely expressed; $\mathrm{S}_{1} \mathrm{P}_{4}$ is expressed in lymphoid and hematopoietic tissues, while $\mathrm{S}_{1} \mathrm{P}_{5}$ is mainly expressed in the central nervous system. ${ }^{23,24} \mathrm{~S} \mathrm{P}_{1}$ is the predominant receptor on lymphocytes and is crucial for the regulation of lymphocyte trafficking. ${ }^{25,26}$ In the central nervous system, $\mathrm{S}_{1} \mathrm{P}_{5}$ and $\mathrm{S}_{1} \mathrm{P}_{1}$ are predominantly expressed by oligodendrocytes, a target of immune attack in multiple sclerosis. ${ }^{27-30}$ The efficacy of fingolimod in experimental autoimmune encephalomyelitis, and in clinical trials of multiple sclerosis is largely attributed to its activity on $\mathrm{S}_{1} \mathrm{P}_{1}$ receptors on lymphocytes and endothelial cells. ${ }^{19,31-34}$ Other possible actions leading to the favorable clinical outcome, including a direct central nervous system effect of fingolimod, are currently being investigated. The chemical name of fingolimod is 2-amino-2-[2-(4-octylphenyl)ethyl]propane1,3-diol hydrochloride, and its chemical structure is shown in Figure 1. It is water soluble at low micromolar concentrations, with a molecular weight of 343.94 .

\section{Mode of action}

FTY720 is a structural analog of intracellular sphingosine, a metabolic product of sphingomyelin, which is a constituent of the cell membrane. Like its analog, FTY720 is rapidly phosphorylated in vivo, yielding to FTY720-phosphate (FTY720-P). In vitro, FTY720-P can bind to four out of the five $\mathrm{S} 1 \mathrm{P}$ receptors, namely $\mathrm{S}_{1} \mathrm{P}_{1}, \mathrm{~S}_{1} \mathrm{P}_{3}, \mathrm{~S}_{1} \mathrm{P}_{4}$, and $\mathrm{S}_{1} \mathrm{P}_{5}$. 
The therapeutic effects of FTY720 have been attributed to the action of the drug on the $\mathrm{S}_{1} \mathrm{P}_{1}$ receptor. In particular, downmodulation of $\mathrm{S} \mathrm{P}_{1}$ on lymphocytes slows the egress of lymphocytes from lymph nodes and recirculation to the central

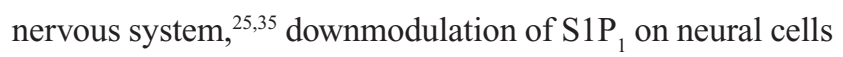
may reduce astrogliosis, ${ }^{30,36-41}$ and downmodulation of $\mathrm{S} \mathrm{P}_{1}$ on migrating endothelial cells inhibits angiogenesis during chronic neuroinflammation. ${ }^{42}$ FTY720 also regulates the migration of B cells and dendritic cells, and enhances endothelial barrier function. ${ }^{43-46}$ Taken together, modes of action of FTY720 render the drug unique when compared with other multiple sclerosis therapies, particularly in terms of its potential neuroprotective and neuroregenerative effect.

\section{Pharmacokinetics}

After oral administration in humans, FTY720 is extensively absorbed ( $\geq 85 \%$ ), with a high apparent absolute oral bioavailability (93\%). Absorption is not affected by food. Studies in renal transplant recipients showed a linear, dosedependent relationship for the maximum concentration and the area under the concentration-time curve at a dosing range of $0.125-5.0 \mathrm{mg} /$ day. ${ }^{47}$ Steady-state is reached in $1-2$ months during once-daily dosing, with an estimated 12 -fold accumulation of blood levels from first dose to steady state. FTY720 distributes in red blood cells, with a fraction in blood of $86 \%$, whereas FTY720-P has a smaller uptake in blood of $<17 \%$. Both FTY720 and FTY720-P are highly protein bound $(>99.7 \%)$. Protein binding is not altered by renal or hepatic impairment. FTY720 is mainly transformed by reversible stereoselective phosphorylation to FTY720-P, the active moiety. Therefore, drug interactions will not be a major issue, although agents that inhibit CYP4F activity may increase blood levels of fingolimod as recently reported for ketoconazole. ${ }^{48}$ FTY720 and FTY720-P are in dynamic equilibrium at steady state. Blood clearance of FTY720 is low (6.3 $\pm 2.3 \mathrm{~L} /$ hour $)$, with a long average apparent terminal half-life (6-9 days). FTY720-P clearance is in parallel with FTY720 in the terminal phase, with similar half-lives for both. After oral administration, about $81 \%$ is slowly excreted in the urine as inactive metabolites. About $2.5 \%$ of FTY720 and FTY720-P are excreted intact in the feces. ${ }^{49}$

\section{Pharmacodynamics}

Three main pharmacodynamic effects of FTY720 have been identified, ie, reduction of lymphocyte count, decrease of heart rate, and increased resistance of the small airways.

Lymphopenia is due to trapping of lymphocytes inside the secondary lymphoid organs. ${ }^{26,50,51}$ Blood lymphocyte counts reach a dose- and concentration-dependent nadir about six hours after the first dose. The nadir is maintained during daily dosing. At a $5 \mathrm{mg}$ daily dose, up to $85 \%$ reduction in peripheral lymphocyte counts can occur. After dosing cessation, the lymphocyte count begins to increase within 2-3 days, with recovery of a normal lymphocyte count within 1-2 weeks after the termination of treatment in the majority of subjects on FTY720 $0.5 \mathrm{mg}$ and $1.25 \mathrm{mg} .{ }^{49,52}$ However, not all lymphocyte subsets are equally affected, and antibody responses are differentially impaired, depending on the localization and dissemination of the antigen. FTY720 inhibits the induction of high-affinity, class-switched IgG antibodies after local administration of $\mathrm{T}$ cell-dependent antigens, whereas the production of low-affinity IgM antibody is not impaired. ${ }^{53,54}$ Therefore, FTY720 may

Table 2 Clinical and magnetic resonance imaging efficacy of FTY720 in the Phase II and III trials

\begin{tabular}{|c|c|c|c|c|c|c|c|c|c|}
\hline \multirow[t]{3}{*}{ Endpoints } & \multicolumn{3}{|c|}{ Phase II trial } & \multicolumn{3}{|c|}{ FREEDOMS } & \multicolumn{3}{|c|}{ TRANSFORMS } \\
\hline & Placebo & FTY720 & FTY720 & Placebo & FTY720 & FTY720 & IFN $\beta-I a$ & FTY720 & FTY720 \\
\hline & & $1.25 \mathrm{mg}$ & $5.0 \mathrm{mg}$ & & $1.25 \mathrm{mg}$ & $0.5 \mathrm{mg}$ & & $1.25 \mathrm{mg}$ & $0.5 \mathrm{mg}$ \\
\hline \multicolumn{10}{|l|}{ Clinical } \\
\hline Annualized relapse rate & 0.77 & 0.35 & 0.36 & 0.40 & 0.16 & 0.18 & 0.33 & 0.2 & 0.16 \\
\hline Relapse-free patients (\%) & 66 & 86 & 86 & 45.6 & 74.7 & 70.4 & 69.3 & 79.8 & 82.6 \\
\hline Absence of disability & 80 & 90 & 85 & 75.9 & 83.4 & 82.3 & 92.1 & 93.3 & 94.1 \\
\hline \multicolumn{10}{|l|}{ progression on the EDSS (\%) } \\
\hline \multicolumn{10}{|l|}{ MRI } \\
\hline gd+ lesions (n) & $2.2 \pm 4.3$ & $1.3 \pm 5.8$ & $0.3 \pm 0.7$ & $\mathrm{I} . \mathrm{I} \pm 2.4$ & $0.2 \pm 1.1$ & $0.2 \pm 0.8$ & $0.51 \pm 1.86$ & $0.14 \pm 0.58$ & $0.23 \pm 0.97$ \\
\hline Absence of gd+ lesions (\%) & 47 & 77 & 82 & 65.1 & 89.8 & 89.7 & 80.8 & 91.2 & 90.1 \\
\hline New T2 lesions (n) & $6.4 \pm 9.2$ & $3.0 \pm 8.6$ & $1.9 \pm 2.6$ & $9.8 \pm 13.2$ & $2.5 \pm 5.5$ & $2.5 \pm 7.2$ & $2.6 \pm 5.8$ & $1.5 \pm 2.7$ & $1.7 \pm 3.9$ \\
\hline $\begin{array}{l}\text { Change in brain volume } \\
\text { from baseline }\end{array}$ & -0.31 & -0.22 & -0.40 & $-|.3|$ & -0.89 & -0.84 & -0.45 & -0.30 & -0.31 \\
\hline
\end{tabular}

Abbreviations: MRI, magnetic resonance imaging; IFN $\beta$, interferon beta; Gd+, gadolinium enhancing; EDSS, Expanded Disability Status Scale; FREEDOMS, FTY720 Research Evaluating Effects of Daily Oral therapy in Multiple Sclerosis;TRANSFORMS, Trial Assessing Injectable Interferon versus FTY720 Oral in Relapsing-Remitting Multiple Sclerosis. 
inhibit responses to antigens which require lymphocyte trafficking, but does not impair humoral immunity when the antigen is widely distributed to most lymphoid organs.

Similar to S1P, FTY720-P activates the cardiac G proteingated potassium channel, resulting in lowering of heart rate. In the presence of persistent FTY720 exposure, S1P receptors are expected to internalize, attenuating the cardiac effect over time. The effect of FTY720 on heart rate can be considered similar to that of vagal mediation, and can include mild to moderate heart rate slowing and atrioventricular block (first- and second-degree Type I Wenckebach).

The acute agonist effects of FTY720 on S1P receptors in bronchial smooth muscle leads to mild bronchoconstriction. With regard to cardiac effects, the internalization of receptors over time is hypothesized to result in the attenuation of the pulmonary actions.

\section{Use in multiple sclerosis Efficacy}

The earliest data on the efficacy of FTY720 in multiple sclerosis comes from a double-blind, placebo-controlled Phase II clinical trial. ${ }^{55}$ A total of 281 patients were randomized to receive two doses of FTY720 (1.25 or $5 \mathrm{mg}$ ) or placebo. Endpoints were analyzed at two time points, ie, months 0-6 (core phase) and at months 7-12 (extension phase). Blinding was maintained in the extension phase of the trial, and the previous placebo group was randomized to the two dose strengths of fingolimod, whereas the previously assigned fingolimod groups continued their existing treatment. The primary endpoint of the study was the total number of contrast-enhancing lesions per patient accumulating over the course of six months. Secondary MRI measures at six months included the percentage of patients free of contrast-enhancing lesions, the volume of gadoliniumenhancing lesions, the total number of new T2 lesions, change in T2 lesion volumes from baseline MRI, and total brain volume. Secondary clinical endpoints analyzed at six months included annualized relapse rate, the total number of relapses, relative reduction in relapse rate versus placebo, and the proportion of relapse-free patients. At six months, both doses of FTY720 showed a significant effect in reducing the total cumulative number of contrast-enhancing lesions (Table 2). Moreover, despite the relatively short duration of the trial, the majority of the secondary MRI endpoints were also met (Table 2). The beneficial effect of fingolimod was also maintained during the extension phase. Furthermore, patients who switched from placebo to the active drug experienced a robust reduction in the number of contrast-enhancing lesions (within-group comparison at month 6 versus month 12). There was no effect of FTY720 on the tertiary outcome measure of disability, as measured on the Expanded Disability Status Scale (EDSS).

The efficacy of FTY720 appeared to be comparable at both the low and high doses, but the dosage of $5 \mathrm{mg}$ was associated with a higher risk of side effects. Therefore, the higher dosage was abandoned, and Phase III trials of fingolimod were planned for the $1.25 \mathrm{mg}$ dose and testing a lower dose of $0.5 \mathrm{mg}$. The first Phase III study of FTY720 in multiple sclerosis was a randomized, double-blind, parallel-group study, ie, TRANSFORMS (Trial Assessing Injectable Interferon versus FTY720 Oral in Relapsing-Remitting Multiple Sclerosis). ${ }^{34}$ This was a three-arm study assessing the effects of daily doses of fingolimod 0.5 and $1.25 \mathrm{mg}$, compared with intramuscular IFN- $\beta 1$ a once a week, over a 12-month period. A total of 1292 patients were randomized to the three arms in a 1:1:1 ratio. Approximately one-half of the patients in the three groups had received previous treatment with disease-modifying drugs for multiple sclerosis (55\%-58\%). The primary efficacy endpoint was the annualized relapse rate. The main secondary endpoints were the number of new or enlarged T2 lesions at 12 months and time to confirmed disability progression as measured on the EDSS and the Multiple Sclerosis Functional Composite (MSFC).

TRANSFORMS was a success, because all endpoints (both primary and secondary) were met (Table 2). The results were not affected by previous treatment with other immunomodulators. In comparison with IFN- $\beta 1 \mathrm{a}$, the 0.5 and $1.25 \mathrm{mg}$ doses of fingolimod reduced the annualized relapse rate by approximately $52 \%$ and $39 \%$, respectively. Both doses of FTY720 delayed the time to the first relapse, decreased the proportion of patients with confirmed relapses, and decreased the number of new MRI lesions and volume of contrast-enhancing lesions (Table 2). Even though disability was not a primary objective of the trial and the study was not powered to evaluate disability progression, FTY720 showed a significant effect on MSFC score when compared with IFN- $\beta 1 \mathrm{a}$. Progression on the EDSS did not significantly differ between FTY720 and IFN- $\beta 1$ a therapy. One of the most compelling results of TRANSFORMS for the treatment of relapsing-remitting multiple sclerosis was the evidence of higher efficacy of the oral drug in comparison with that of the currently accepted immunomodulatory agent.

The second Phase III trial of fingolimod was FREEDOMS (FTY720 Research Evaluating Effects of Daily Oral therapy 
in Multiple Sclerosis). ${ }^{33}$ This study assessed the effects of daily doses of FTY720 $0.5 \mathrm{mg}$ or $1.25 \mathrm{mg}$, compared with placebo over a 24-month follow-up period. A total of 1272 patients were randomized with a 1:1:1 ratio. The proportion of reviously treated patients was slightly lower than that of TRANSFORMS (40\%-43\%). However, the primary and secondary endpoints were similar to those described in TRANSFORMS. This study confirmed the beneficial effect of fingolimod in relapsing-remitting multiple sclerosis. Compared with placebo, the $0.5 \mathrm{mg}$ and $1.25 \mathrm{mg}$ doses of fingolimod reduced the annualized relapse rate by $54 \%$ and $60 \%$, respectively. Time to the first relapse was significantly delayed and the proportion of relapse-free patients was significantly higher in the FTY720 groups. It is worth noting that in FREEDOMS, both the low and high doses of FTY720 were proven to be effective for lowering the risk of disability progression. In particular, the hazard ratio of progression on the EDSS confirmed at three months was 0.70 for the low dosage and 0.68 for the high dosage. The corresponding values for EDSS progression confirmed at six months were 0.63 and 0.60 . The MSFC scores remained consistently stable in both FTY720 groups, whereas they worsened in the placebo group. With regard to MRI parameters, both doses of fingolimod caused a significant reduction in the number of contrast-enhancing lesions at 24 months, as well as in the number of new or enlarged T2 lesions and in T2 lesion volume change from baseline. The efficacy of FTY720 was maintained, also merging the MRI parameters in a unique score including both the absence of contrast-enhancing lesions at 24 months and new T2 lesions from baseline (Table 2). Interestingly, both doses of FTY720 significantly reduced T1 lesion volumes and brain volume loss when compared with placebo. The latter two MRI parameters are believed to be surrogate markers of disease activity in terms of brain tissue damage, and their improvement may be related to a neuroprotective action of the drug. Moreover, the lack of "pseudoatrophy" (brain volume loss observed in the first 6-12 months of treatment due to reduced inflammation and related water content) in FTY720 trials seems to confirm that the mode of action of fingolimod may involve other effects (neuroprotective, neuroregenerative) beyond its anti-inflammatory actions.

On the whole, results from Phase II and III trials of FTY720 for the treatment of relapsing-remitting multiple sclerosis are very promising. Further insights are expected from the ongoing extension of the fingolimod Phase III trial, FREEDOMS II. Patients originally randomized to placebo or fingolimod $1.25 \mathrm{mg}$ are switched to the lower $0.5 \mathrm{mg}$ dose, and this dose appears to be safer. Finally, in view of the neuroprotective and neuroregenerative potential of FTY720, a Phase III trial INFORMS (A double-blind, randomized, multicenter, placebo-controlled parallel-group study comparing the efficacy and safety of $1.25 \mathrm{mg}$ FTY720 administered orally once daily versus placebo in patient with primaryprogressive multiple sclerosis) has been launched in patients with primary progressive multiple sclerosis.

\section{Safety and tolerability}

In general, FTY720 was shown to be well tolerated in all the Phase II and III studies. ${ }^{33,34,55}$ In the Phase II core study, discontinuation rates due to side effects were low across all groups. No deaths were reported. Minor side effects included nasopharyngitis, headache, diarrhea, and nausea. Nasopharyngitis, diarrhea, and nausea were significantly more frequent in the $5 \mathrm{mg}$ dose group than in the placebo group. The difference was not significant for the $1.25 \mathrm{mg}$ group. As expected, lymphopenia was common, but was mainly asymptomatic. Peripheral blood lymphocyte counts dropped to $20 \%-30 \%$ of the baseline value. Among serious adverse events, bradycardia, chest pain, first-degree atrioventricular block, dyspnea, hypertension, and an increase in liver enzymes with jaundice were reported. A squamous cell carcinoma also occurred. These events were absent in the placebo group. In the extension period of the Phase II trials, two severe infections occurred in patients who switched from placebo to active treatment (facial herpes zoster on $5 \mathrm{mg}$ and enterocolitis on $1.25 \mathrm{mg}$ ). Moreover, in the $5 \mathrm{mg}$ dose group, a posterior reversible encephalopathy syndrome was diagnosed in a patient with no prior history of hypertension or renal disease, which improved promptly after drug discontinuation.

With regard to cardiac effects, FTY720 caused a reduction in heart rate within the first six hours by a mean 13.8 beats/ minute in the $1.25 \mathrm{mg}$ group and 16.6 beats/minutes in the $5 \mathrm{mg}$ group. However, as expected from its pharmacodynamics, the reduction in heart rate improved back towards baseline with continued FTY720 treatment. Bradycardia was symptomatic in one patient who switched from placebo to the $1.25 \mathrm{mg}$ dose and three patients who switched to the $5 \mathrm{mg}$ dose. All episodes of symptomatic bradycardia occurred within 24 hours, and resolved spontaneously. Moreover, transient second-degree Wenckebach atrioventricular block occurred in four patients receiving FTY720 $1.25 \mathrm{mg}$ and five patients receiving $5 \mathrm{mg}$. With regard to bradycardia, atrioventricular block occurred within 24 hours of the start of therapy. One patient receiving FTY720 $5 \mathrm{mg}$ experienced a single four-beat episode of nonsustained ventricular tachycardia. Blood pressure decreased to 5-6 mmHg below baseline within 4-5 hours 
of fingolimod treatment. However, this was followed by a sustained increase in blood pressure of 4-6 $\mathrm{mmHg}$ above baseline values after two months of fingolimod, with no further increase over time. For pulmonary effects, forced expiratory volume in one second $\left(\mathrm{FEV}_{1}\right)$ significantly reduced from baseline values in $8.8 \%$ of patients treated with the high-dose of FTY720 in comparison with $2.8 \%$ of patients in the lowdose group and $1.9 \%$ of patients on placebo. After six months of treatment, predicted forced vital capacity (FVC) values decreased significantly by $0.8 \%$ and $3.2 \%$ in the 1.25 and $5 \mathrm{mg}$ groups, respectively. However, in the extension phase, $\mathrm{FEV}_{1}$, FVC, and CO diffusion capacity was not different from values observed at six months. In general, serious adverse events were more frequent in the high-dose group ( $5 \mathrm{mg}$ ). Indeed, the dosage of $5 \mathrm{mg}$ was abandoned and further investigations focused on the dosage of $1.25 \mathrm{mg}$ and $0.5 \mathrm{mg}$.

In TRANSFORMS, the overall incidence of adverse events was low. However, two deaths occurred in the $1.25 \mathrm{mg}$ group. Both deaths were secondary to infections. In one case, fatal infection was a disseminated varicella zoster infection. The patient had no prior exposure to chickenpox and the primary exposure to chickenpox occurred while on FTY720 $0.5 \mathrm{mg}$ and concurrent steroid treatment for multiple sclerosis relapse. The other patient died of herpes simplex encephalitis. Two additional patients died after the study was discontinued, both in the low-dose fingolimod group. One patient died from aspiration pneumonia 11 months after drug discontinuation. The second patient died from metastatic breast cancer 10 months after stopping fingolimod. In TRANSFORMS, four other serious infections were reported in patients treated with FTY720, ie, two herpes simplex virus infections and two cases of appendicitis. Two appendicitis cases and one herpes simplex virus infection were also reported in the IFN- $\beta 1$ a group.

Other mild herpes simplex virus infections were observed in 12 patients receiving IFN- $\beta 1 \mathrm{a}$, nine receiving FTY720 $0.5 \mathrm{mg}$, and 23 receiving FTY720 $1.25 \mathrm{mg}$. As reported in the Phase II trial, fingolimod was associated with bradycardia, second-degree atrioventricular block, and elevated liver enzymes. Respiratory events were mild and with a greater frequency on the $1.25 \mathrm{mg}$ dose. Furthermore, two patients on $0.5 \mathrm{mg}$ and four patients on $1.25 \mathrm{mg}$ had macular edema, diagnosed within four months from the start of FTY720 treatment. In most cases, macular edema resolved within three months after drug discontinuation. Cancers were diagnosed in 12 subjects receiving FTY720, comprising skin cancers in 10 patients (all successfully treated with excision) and breast cancers in four patients, three of which were detected within four months of the start of therapy and one diagnosed after 11 months. One basal cell carcinoma was also observed in the IFN- $\beta 1$ a group.

The incidence of adverse events was also low in FREEDOMS. However, three deaths occurred, two in the placebo group and one in the FTY720 $1.25 \mathrm{mg}$ group. Deaths in the placebo group were due to pulmonary embolism and a road traffic accident. The death in the fingolimod group was due to suicide. The risk of infection was similar in all groups. Infections include urinary tract infections, herpes simplex virus infections, and lower respiratory infections. Bradycardia was associated with FTY720, and required treatment in only two cases. First-degree atrioventricular block was reported in 20 patients on FTY720 $0.5 \mathrm{mg}$, 37 patients on $1.25 \mathrm{mg}$, and in six patients receiving placebo; second-degree atrioventricular block occurred in one patient receiving $0.5 \mathrm{mg}$ and four patients on $1.25 \mathrm{mg}$. All the effects were observed within the first 24 hours after FTY720 onset; with continued drug administration, no significant effect on heart rate or conduction was seen over the 24-month study. FTY720 was also associated with a mild increase in mean systolic blood pressure (1.9-3.6 mmHg). Macular edema occurred in seven patients, all receiving FTY720 $1.25 \mathrm{mg}$. It was diagnosed within three months after drug initiation and resolved within six months after drug discontinuation. Finally, skin cancers occurred in 11 patients (three receiving fingolimod $1.25 \mathrm{mg}$, four receiving $0.5 \mathrm{mg}$, and four receiving placebo), all successfully treated by excision.

\section{Conclusion}

Over the last two decades, first-line therapy for multiple sclerosis has been dominated by the use of immunomodulatory drugs, all administered parenterally (intramuscularly or subcutaneously). Until now, one of the most important unmet needs in multiple sclerosis treatment has been efficacious oral therapy. In September 2010, the FDA approved FTY720 (Gilenya ${ }^{\mathrm{TM}}$ ) as first-line therapy for relapsing-remitting multiple sclerosis at a dosage of $0.5 \mathrm{mg} .{ }^{20}$ The decision was made on the basis of efficacy and safety data from the Phase III TRANSFORMS and FREEDOMS trials. ${ }^{33,34}$ A baseline electroencephalogram and monitoring for bradycardia in the first six hours after the first administration is recommended. Monitoring for infective, ophthalmologic, liver, and pulmonary complications is also required.

The introduction of FTY720 among the available treatment strategies for relapsing-remitting multiple sclerosis is promising and exciting. Clinical trials have clearly provided robust evidence of the efficacy of the drug in reducing the relapse rate and, to a lesser extent, the risk of disability progression. 
Moreover, the oral route of administration should achieve higher levels of treatment adherence in comparison with currently used immunomodulatory therapies. However, some caution is necessary. First, although the efficacy of immunomodulatory therapy appeared to be lower than for FTY720 in TRANSFORMS and parenteral administration is associated with poorer compliance than for oral preparations, the safety profiles of IFN- $\beta$ and glatiramer acetate are well established by lengthy postmarketing experience. Fingolimod has been associated with a higher risk of potentially severe adverse events, including infections, cardiac events, and cancers, so strict monitoring of long-term safety is necessary. Some examples can be drawn from the experience with natalizumab. Biogen initiated an international program of surveillance. Moreover, a similar registry may be developed at a national level, as occurred in Italy, where a registry of all cases treated with natalizumab is kept by the National Drugs Agency. ${ }^{13-15}$ Second, multiple sclerosis frequently affects women in their child-bearing years. Information on the effects of FTY720 in pregnancy is lacking. In animal studies, fingolimod demonstrated developmental toxicity, including teratogenicity and embryolethality in rats. There are no relevant data in humans, and a pregnancy registry has been developed. In the meantime, evidence is accumulating on the safety of immunomodulatory drugs in pregnancy and fetal outcomes. ${ }^{56}$

However, despite these caveats, fingolimod represents a great advance in the treatment of relapsing-remitting multiple sclerosis. Its efficacy is sustained by a strong antiinflammatory effect, together with potential neuroprotective and neuroregenerative properties and the drug was generally safe and well tolerated in clinical trials. Its broad spectrum of action renders fingolimod a possible candidate for further research in other forms of multiple sclerosis, namely primary progressive multiple sclerosis and secondary progressive multiple sclerosis, in which inflammatory activity is less pronounced, and benefit may be derived from its neuroprotective effects.

\section{Disclosure}

The author has received research grants from Biogen Idec, Sanofi-aventis, Bayer Schering, and Merck Serono, as well as compensation for participation on the advisory board of Biogen Idec.

\section{References}

1. Compston A, Coles A. Multiple sclerosis. Lancet. 2008;372(9648): $1502-1517$.

2. Lucchinetti C, Bruck W, Parisi J, Scheithauer B, Rodriguez M, Lassmann H. Heterogeneity of multiple sclerosis lesions: Implications for the pathogenesis of demyelination. Ann Neurol. 2000;47(6):707-717.
3. Lassmann H. Recent neuropathological findings in multiple sclerosis - implications for diagnosis and therapy. J Neurol. 2004;251 Suppl 4: IV2-IV5.

4. Wiendl H, Toyka KV, Rieckmann P, Gold R, Hartung HP, Hohlfeld R. Basic and escalating immunomodulatory treatments in multiple sclerosis: Current therapeutic recommendations. J Neurol. 2008;255(10): $1449-1463$.

5. The IFNB Multiple Sclerosis Study Group. Interferon beta- $1 \mathrm{~b}$ is effective in relapsing-remitting multiple sclerosis. I. Clinical results of a multicenter, randomized, double-blind, placebo-controlled trial. Neurology. 1993;43(4):655-661.

6. Jacobs LD, Cookfair DL, Rudick RA, et al. Intramuscular interferon beta-1a for disease progression in relapsing multiple sclerosis. The Multiple Sclerosis Collaborative Research Group (MSCRG). Ann Neurol. 1996;39(3):285-294.

7. PRISMS (Prevention of Relapses and Disability by Interferon beta-1a Subcutaneously in Multiple Sclerosis) Study Group. Randomised double-blind placebo-controlled study of interferon beta-1a in relapsing/ remitting multiple sclerosis. Lancet. 1998;352(9139):1498-1504.

8. Johnson KP, Brooks BR, Cohen JA, et al. Copolymer 1 reduces relapse rate and improves disability in relapsing-remitting multiple sclerosis: Results of a phase III multicenter, double-blind placebo-controlled trial. The Copolymer 1 Multiple Sclerosis Study Group. Neurology. 1995; 45(7):1268-1276.

9. Goodin DS, Cohen BA, O'Connor P, Kappos L, Stevens JC. Assessment: The use of natalizumab (Tysabri) for the treatment of multiple sclerosis (an evidence-based review): Report of the Therapeutics and Technology Assessment Subcommittee of the American Academy of Neurology. Neurology. 2008;71(10):766-773.

10. O'Connor P, Filippi M, Arnason B, et al. 250 microg or 500 microg interferon beta- $1 \mathrm{~b}$ versus $20 \mathrm{mg}$ glatiramer acetate in relapsing-remitting multiple sclerosis: A prospective, randomised, multicentre study. Lancet Neurol. 2009;8(10):889-897.

11. Mikol DD, Barkhof F, Chang P, et al. Comparison of subcutaneous interferon beta-1a with glatiramer acetate in patients with relapsing multiple sclerosis (the REbif vs Glatiramer Acetate in Relapsing MS Disease [REGARD] study): A multicentre, randomised, parallel, open-label trial. Lancet Neurol. 2008;7(10): 903-914.

12. Marriott JJ, Miyasaki JM, Gronseth G, O'Connor PW. Evidence report: The efficacy and safety of mitoxantrone (Novantrone) in the treatment of multiple sclerosis: Report of the Therapeutics and Technology Assessment Subcommittee of the American Academy of Neurology. Neurology. 2010;74(18):1463-1470.

13. Mancardi GL, Amato MP, D’Alessandro R, et al. Natalizumab: A country-based surveillance program. Neurol Sci. 2008;29 Suppl 2: S235-S237.

14. Tedeschi G, Amato MP, D'Alessandro R, et al. The pharmacovigilance program on natalizumab in Italy: 2 years of experience. Neurol Sci. 2009;30 Suppl 2:S163-S165.

15. Mancardi GL, Tedeschi G, Amato MP, et al. Three years of experience: The Italian registry and safety data update. Neurol Sci. 2010 Jul 20. [Epub ahead of print].

16. Portaccio E, Amato MP. Improving compliance with interferon-beta therapy in patients with multiple sclerosis. CNS Drugs. 2009;23(6): 453-462.

17. Rammohan KW, Shoemaker J. Emerging multiple sclerosis oral therapies. Neurology. 2010;74 Suppl 1:S47-S53.

18. Giovannoni G, Comi G, Cook S, et al. A placebo-controlled trial of oral cladribine for relapsing multiple sclerosis. N Engl J Med. 2010; 362(5):416-426.

19. Brinkmann V, Davis MD, Heise CE, et al. The immune modulator FTY720 targets sphingosine 1-phosphate receptors. J Biol Chem. 2002; 277(24):21453-21457.

20. Gilenya label and approval history. Available from: http://www.access data.fda.gov/scripts/cder/drugsatfda/index.cfm?fuseaction=Search. Label_ApprovalHistory\#apphist. Accessed 2010 Oct 8. 
21. Fujita T, Inoue $\mathrm{K}$, Yamamoto $\mathrm{S}$, et al. Fungal metabolites. Part 11. A potent immunosuppressive activity found in Isaria sinclairii metabolite. J Antibiot (Tokyo). 1994;47(2):208-215.

22. Spiegel S, Milstien S. Exogenous and intracellularly generated sphingosine 1-phosphate can regulate cellular processes by divergent pathways. Biochem Soc Trans. 2003;31(Pt 6):1216-1219.

23. Ishii I, Ye X, Friedman B, et al. Marked perinatal lethality and cellular signaling deficits in mice null for the two sphingosine 1-phosphate (S1P) receptors, S1P(2)/LP(B2)/EDG-5 and S1P(3)/LP(B3)/EDG-3 J Biol Chem. 2002;277(28):25152-25159.

24. Brinkmann V. Sphingosine 1-phosphate receptors in health and disease: Mechanistic insights from gene deletion studies and reverse pharmacology. Pharmacol Ther. 2007;115(1):84-105

25. Matloubian M, Lo CG, Cinamon G, et al. Lymphocyte egress from thymus and peripheral lymphoid organs is dependent on S1P receptor 1. Nature. 2004;427(6972):355-360.

26. Mandala S, Hajdu R, Bergstrom J, et al. Alteration of lymphocyte trafficking by sphingosine-1-phosphate receptor agonists. Science. 2002; 296(5566):346-349.

27. Terai K, Soga T, Takahashi M, et al. Edg- 8 receptors are preferentially expressed in oligodendrocyte lineage cells of the rat central nervous system. Neuroscience. 2003;116(4):1053-1062.

28. Yu N, Lariosa-Willingham KD, Lin FF, Webb M, Rao TS. Characterization of lysophosphatidic acid and sphingosine-1-phosphate-mediated signal transduction in rat cortical oligodendrocytes. Glia. 2004;45(1): $17-27$.

29. Jaillard C, Harrison S, Stankoff B, et al. Edg8/S1P5: An oligodendroglial receptor with dual function on process retraction and cell survival. J Neurosci. 2005;25(6):1459-1469.

30. Jung CG, Kim HJ, Miron VE, et al. Functional consequences of S1P receptor modulation in rat oligodendroglial lineage cells. Glia. 2007; 55(16):1656-1667.

31. Kataoka H, Sugahara K, Shimano K, et al. FTY720, sphingosine 1-phosphate receptor modulator, ameliorates experimental autoimmune encephalomyelitis by inhibition of T cell infiltration. Cell Mol Immunol. 2005;2(6):439-448.

32. Balatoni B, Storch MK, Swoboda EM, et al. FTY720 sustains and restores neuronal function in the DA rat model of MOG-induced experimental autoimmune encephalomyelitis. Brain Res Bull. 2007; 74(5):307-316.

33. Kappos L, Radue EW, O'Connor P, et al. A placebo-controlled trial of oral fingolimod in relapsing multiple sclerosis. N Engl J Med. 2010; 362(5):387-401

34. Cohen JA, Barkhof F, Comi G, et al. Oral fingolimod or intramuscular interferon for relapsing multiple sclerosis. N Engl J Med. 2010;362(5): 402-415.

35. Fujino M, Funeshima N, Kitazawa Y, et al. Amelioration of experimental autoimmune encephalomyelitis in Lewis rats by FTY720 treatment. $J$ Pharmacol Exp Ther. 2003;305(1):70-77.

36. Sorensen SD, Nicole O, Peavy RD, et al. Common signaling pathways link activation of murine PAR-1, LPA, and S1P receptors to proliferation of astrocytes. Mol Pharmacol. 2003;64(5):1199-1209.

37. Foster CA, Howard LM, Schweitzer A, et al. Brain penetration of the oral immunomodulatory drug FTY720 and its phosphorylation in the central nervous system during experimental autoimmune encephalomyelitis: Consequences for mode of action in multiple sclerosis. J Pharmacol Exp Ther. 2007;323(2):469-475.

\section{Core Evidence}

\section{Publish your work in this journal}

Core Evidence is an international, peer-reviewed open-access journal evaluating the evidence underlying the potential place in therapy of drugs throughout their development lifecycle from preclinical to postlaunch. The focus of each review is to evaluate the case for a new drug or class in outcome terms in specific indications and patient groups.
38. Miron VE, Ludwin SK, Darlington PJ, et al. Fingolimod (FTY720) enhances remyelination following demyelination of organotypic cerebellar slices. Am J Pathol. 2010;176(6):2682-2694.

39. Coelho RP, Payne SG, Bittman R, Spiegel S, Sato-Bigbee C. The immunomodulator FTY720 has a direct cytoprotective effect in oligodendrocyte progenitors. J Pharmacol Exp Ther. 2007;323(2): 26-635.

40. Novgorodov AS, El-Alwani M, Bielawski J, Obeid LM, Gudz TI. Activation of sphingosine-1-phosphate receptor S1P5 inhibits oligodendrocyte progenitor migration. FASEB J. 2007;21(7): 1503-1514.

41. Mullershausen F, Craveiro LM, Shin Y, et al. Phosphorylated FTY720 promotes astrocyte migration through sphingosine-1-phosphate receptors. J Neurochem. 2007;102(4):1151-1161.

42. Allende ML, Yamashita T, Proia RL. G-protein-coupled receptor S1P1 acts within endothelial cells to regulate vascular maturation. Blood. 2003;102(10):3665-3667.

43. Lan YY, de Creus A, Colvin BL, et al. The sphingosine-1-phosphate receptor agonist FTY720 modulates dendritic cell trafficking in vivo. Am J Transplant. 2005;5(11):2649-2659.

44. Cinamon G, Zachariah MA, Lam OM, Foss FW Jr, Cyster JG. Follicular shuttling of marginal zone B cells facilitates antigen transport. Nat Immunol. 2008;9(1):54-62.

45. Sanchez T, Estrada-Hernandez T, Paik JH, et al. Phosphorylation and action of the immunomodulator FTY720 inhibits vascular endothelial cell growth factor-induced vascular permeability. J Biol Chem. 2003; 278(47):47281-47290.

46. Kim HJ, Jung CG, Dukala D, et al. Fingolimod and related compounds in a spontaneous autoimmune polyneuropathy. J Neuroimmunol. 2009; 214(1-2):93-100.

47. Kahan BD, Karlix JL, Ferguson RM, et al. Pharmacodynamics, pharmacokinetics, and safety of multiple doses of FTY720 in stable renal transplant patients: A multicenter, randomized, placebo-controlled, phase I study. Transplantation. 2003;76(7):1079-1084.

48. Kovarik JM, Dole K, Riviere GJ, et al. Ketoconazole increases fingolimod blood levels in a drug interaction via CYP4F2 inhibition. J Clin Pharmacol. 2009;49(2):212-218.

49. Kovarik JM, Schmouder R, Barilla D, Riviere GJ, Wang Y, Hunt T. Multiple-dose FTY720: Tolerability, pharmacokinetics, and lymphocyte responses in healthy subjects. J Clin Pharmacol. 200;44(5):532-537.

50. Graeler M, Shankar G, Goetzl EJ. Cutting edge: Suppression of T cell chemotaxis by sphingosine 1-phosphate. J Immunol. 2002;169(8): 4084-4087.

51. Kabashima K, Haynes NM, Xu Y, et al. Plasma cell S1P1 expression determines secondary lymphoid organ retention versus bone marrow tropism. J Exp Med. 2006;203(12):2683-2690.

52. Kovarik JM, Schmouder R, Barilla D, Wang Y, Kraus G. Single-dose FTY720 pharmacokinetics, food effect, and pharmacological responses in healthy subjects. Br J Clin Pharmacol. 2004;57(5):586-591.

53. Mehling M, Brinkmann V, Antel J, et al. FTY720 therapy exerts differential effects on T cell subsets in multiple sclerosis. Neurology. 2008; 71(16):1261-1267.

54. Han S, Zhang X, Wang G, et al. FTY720 suppresses humoral immunity by inhibiting germinal center reaction. Blood. 2004;104(13): 4129-4133.

55. Kappos L, Antel J, Comi G, et al. Oral fingolimod (FTY720) for relapsing multiple sclerosis. N Engl J Med. 2006;355(11):1124-1140.

56. Amato MP, Portaccio E, Ghezzi A, et al. Pregnancy and fetal outcomes after interferon-beta exposure in multiple sclerosis. Neurology. 2010; 75(20):1794-1802.

\section{Dovepress}

The manuscript management system is completely online and includes a very quick and fair peer-review system, which is all easy to use. Visit http://www.dovepress.com/testimonials.php to read real quotes from published authors. 